\title{
CpG-island methylation of the ER promoter in colorectal cancer: analysis of micrometastases in lymph nodes from UICC stage I and II patients
}

\author{
J Harder ${ }^{1,9}$, V Engelstaedter ${ }^{1,9}$, H Usadel ${ }^{1,9}$, S Lassmann ${ }^{2}$, M Werner ${ }^{2}$, P Baier ${ }^{3}$, F Otto ${ }^{4,5}$, M Varbanova', \\ E Schaeffner ${ }^{6}, M^{\circ}$ Olschewski ${ }^{7}$, HE Blum' and OG Opitz ${ }^{*, 8}$ \\ 'Department of Medicine II, University Medical Center, Freiburg, Germany; ${ }^{2}$ Institute of Pathology, University Medical Center, Freiburg, Germany; \\ ${ }^{3}$ Department of Surgery, University Medical Center, Freiburg, Germany; ${ }^{4}$ Department of Medicine I, University Medical Center, Freiburg, Germany; \\ ${ }^{5}$ Tumorzentrum ZeTuP, Center for Tumor Detection, Treatment and Prevention, St Gallen, Switzerland; ${ }^{6}$ Department of Medicine, Charite, Campus \\ Virchow, Berlin, Germany; ${ }^{7}$ Department of Medical Biometry and Statistics, University of Freiburg, Freiburg, Germany; ${ }^{8}$ Tumorzentrum Ludwig \\ Heilmeyer - Comprehensive Cancer Center, Freiburg, Germany
}

Patients with UICC stage II colorectal cancer (CRC) have a risk of approximately $20 \%$ to develop disease recurrence after tumour resection. The presence and significance of micrometastases for locoregional recurrence in these patients lacking histopathological lymph node involvement on routine stained HE sections is undefined. Oestrogen receptor (ER) promoter methylation has earlier been identified in CRC. Therefore, we evaluated the methylation status of the ER promoter in lymph nodes from 49 patients with CRC UICC stage I and II as a molecular marker of micrometastases and predictor of local recurrence. DNA from 574 paraffinembedded lymph nodes was isolated and treated with bisulphite. For the detection of methylated ER promoter sequences, quantitative real-time methylation-specific PCR was used. Of the 49 patients tested, I5 (3I\%) had ER methylation-positive lymph nodes. Thirteen of those (86\%) remained disease free and two (I 4\%) developed local recurrence. In the resected lymph nodes of 34 of the 49 patients (69\%), no ER promoter methylation could be detected and none of these patients experienced a local relapse. The methylation status of the ER promoter in lymph nodes of UICC stage I and II CRC patients may be a useful marker for the identification of patients at a high risk for local recurrence.

British Journal of Cancer (2009) I 00, 360-365. doi:I0.1038/sj.bjc.6604859 www.bjcancer.com

Published online 13 January 2009

(c) 2009 Cancer Research UK

Keywords: molecular marker; colorectal cancer; micrometastases

Colorectal cancer (CRC) is the third most common cancer in western countries with an incidence of 45-60 per 100000 per year in Europe and the United States (Landis et al, 1998). In CRC, the histopathological lymph node status at the time of surgery is one of the main prognostic factors. Adjuvant chemotherapy has been shown to improve disease-free survival by $20-30 \%$ in patients after curative resection for colon cancer metastatic to regional lymph nodes (UICC stage III; Dukes C). In contrast, in UICC stage II disease (T3-4, N0, M0; Dukes stage B), only a minimal survival benefit can be achieved with adjuvant chemotherapy. Therefore, patients with UICC stage II CRC are treated with adjuvant chemotherapy only in the presence of additional negative prognostic factors indicating a high risk for relapse (e.g. undifferentiated tumours, tumour perforation). However, approximately $20 \%$ of the UICC stage II patients develop local recurrence or distant metastases and would potentially benefit from adjuvant

\footnotetext{
*Correspondence: Professor Dr OG Opitz;

E-mail: oliver.opitz@uniklinik-freiburg.de

${ }^{9}$ These authors contributed equally to this work

Received 7 October 2008; revised 3 December 2008; accepted 3

December 2008; published online 13 January 2009
}

chemotherapy. At present, these patients cannot be identified at the time of surgery.

The presence and prognostic relevance of lymph node micrometastases in CRC patients without routine histopathological evidence of lymph node involvement by standard criteria is unclear. Several molecular markers including CEA, CK, MUC2 and p53 have been used to detect micrometastases in regional lymph nodes. However, to date, these markers investigated are unreliable due to low sensitivity and/or low specificity (Sanchez-Cespedes et al, 1999; Noura et al, 2002b; Rosenberg et al, 2002; Ho et al, 2004; Lee et al, 2006). Depending on the respective marker and method used, micrometastases were detected in $20-100 \%$ of resected histologically negative lymph nodes of CRC patients with varying results regarding their prognostic value (Futamura et al, 1998). This wide range of positive results for micrometastases in resected lymph nodes is clearly influenced by differences in the specificity and sensitivity of the candidate markers and detection methods used. In addition, it raises the question of the clinical significance of single tumour cells for disease recurrence.

Issa et al (1994) first described the methylation of CpG (cytosine phospho guanine) islands in the promoter of the oestrogen receptor (ER) in CRC. Non-malignant tissues from thyroid, breast, lung, cervix and prostate were examined for the presence of ER 
promoter methylation and found to be negative (Esteller et al, 2001). In contrast, ER promoter methylation seems to play a role in the early steps of carcinogenesis in several tumour sites including lymphoma, oesophageal cancer and CRC (Issa et al, 1994, 1996; Eads et al, 2000), being present in almost $100 \%$ of primary colorectal tumours. In addition to its potential role in colon carcinogenesis, $\mathrm{CpG}$ island methylation of the ER promoter might therefore be a useful marker for molecular detection of micrometastases in lymph nodes of CRC patients.

In addition to micrometastases, genetic subtypes or distinct molecular signatures of the primary tumour have been linked to the probability of local recurrence (Lenz et al, 1998; Gryfe et al, 2000; Kim et al, 2007). Kim et al (2007) showed a higher recurrence-free survival for patients with microsatellite-instable $(\mathrm{MSI}+)$ tumours and Gryfe et al (2000) could show that MSI + tumours have a decreased likelihood of metastasising to regional lymph nodes. Other molecular markers such as $p 53$ overexpression and thymidylate synthase have also been linked to higher recurrence rates (Lenz et al, 1998). Except for one report, promoter methylation other than hMLH1 and hMSH2, which then leads to MSI, has not been linked to disease recurrence (de Maat et al, 2008). MSI + tumours are more frequent in the right colon (Kim et al, 2007) and define one subtype of CRC (Jass, 2007). Nevertheless, ER promoter methylation is more frequent in the left colon and rectum at least in normal tissue independent of the location of CRC (Issa et al, 1994).

During surgical resection of CRC, draining lymph nodes are removed together with the primary tumour. The number of metastatic lymph nodes, and also the absolute number of resected lymph nodes or as shown in recent reports the lymph node ratio of metastatic to non-metastatic lymph nodes, predicts the likelihood of disease recurrence in CRC stage III patients. This might be explained by the fact that resected metastatic lymph nodes drain into lymph node areas, which are not resected by the surgeon (Yagci et al, 2007). As micrometastases are thought to cause local recurrence through this route, the detection of micrometastases by real-time methylation-specific PCR (rt-MSP) in resected lymph nodes could be a tool to predict local disease recurrence caused by single tumour cells remaining outside the resected area.

Therefore, the aim of this study was to define the value of ER promoter methylation, detected by rt-MSP in resected lymph nodes from patients with CRC UICC stage I and II, as a predictor of local disease recurrence.

\section{MATERIALS AND METHODS}

\section{Study population}

A total of 76 patients were examined in this study (Figure 1). As positive control, primary tumours and microscopically proven metastatic lymph nodes from 14 patients with CRC UICC stage III disease (any T, N1-2, M0) were analysed. As negative control, served lymph nodes from 12 patients obtained from colon resection for non-neoplastic diseases, for example ileus and ulcerative colitis. Fifty consecutive patients with CRC UICC stage I or II disease underwent complete tumour resection at the Department of General and Visceral Surgery at the University Medical Center Freiburg, Germany, between January 2000 and December 2002. One patient was lost to follow-up, therefore 49 patients were analysed for the presence of micrometastases. The latter only included patients with completely (R0) resected sporadic CRC, and histopathologically classified pN0 (negative) lymph nodes were analysed in this retrospective study. The patients with rectal cancer did not have neoadjuvant therapy. Microsatellite status was assessed earlier in 27 of these 49 primary CRCs (Gerlach et al, 2006). In all, 7 out of $27(26 \%)$ of the cases were MSI positive and 20 out of $27(74 \%)$ were MSI negative.

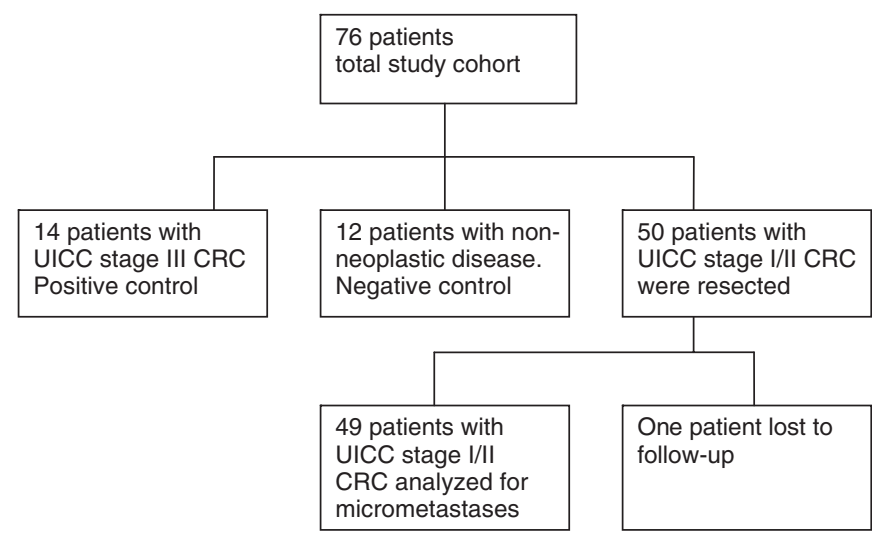

Figure I The whole study population comprised 76 patients. Fourteen patients were in the positive and 12 in the negative control group. Fifty patients had been resected for stage I or II CRC. As one patient was lost to follow-up, 49 patients were analysed by ER promoter rt-MSP.

\section{Lymph node processing and DNA extraction}

Serial sections of surgically resected lymph nodes were analysed after having been completely processed by formalin fixation, paraffin embedding and routine diagnostics of histopathological TNM classification, for the presence of micrometastases by rt-MSP. In total, 574 lymph nodes (mean 9.8 per patient, range 1 -29) were available for analysis. Case-specific clinicopathological and experimental parameters, including the number of lymph nodes analysed by rt-MSP and clinical follow-up, are given in Table 2.

Six serial sections were used for DNA isolation $(6 \times 10 \mu \mathrm{m})$ and one section $(3 \mu \mathrm{m})$ for $\mathrm{HE}$ staining. The lymph nodes were manually microdissected and pooled for DNA isolation to yield one sample per patient. Tissue sections were deparaffinised in xylene and rehydrated using ethanol in decreasing concentrations. Rehydrated tissue sections were digested using proteinase $\mathrm{K}$ dissolved in TE buffer diluted at 1:10 in distilled water. Genomic DNA was isolated using a commercially available DNA extraction kit (DNeasy ${ }^{\mathbb{R}}$; Qiagen, Hilden, Germany). The DNA concentration of each patient sample was measured (Nanodrop ${ }^{\mathbb{B}}$; PeqLab, Erlangen, Germany) with a mean concentration of $157 \mathrm{ng} \mu \mathrm{l}^{-1}$ $\left( \pm 82 \mathrm{ng} \mu \mathrm{l}^{-1}\right.$ ). Two micrograms of each DNA sample were treated with sodium bisulphite converting unmethylated cytosine to uracil and leaving methylated cytosine intact, as described by Herman et al (1996). After bisulphite modification, the DNA was purified and eluted in $20 \mu \mathrm{l} \mathrm{H}_{2} \mathrm{O}$.

\section{ER promoter analysis}

To define the most suitable methylated ER promoter region, we first established a conventional MSP. Lapidus et al (1998) divided the CpG island of the ER promoter into six regions (ER1-ER6) and tested them for methylation and its functional relevance regarding gene expression in breast cancer cell lines. Comparison of the different primer sets showed the region ER4 of the CpG island to be most specific. This region was identical to the region analysed by Issa et al (1994) for its functional relevance. The primer and probe of the more sensitive rt-MSP used to analyse the study population as well as the positive and negative control group also cover this region and were published recently (Eads et al, 2000). Overall, the primer sequences used are as follows: MSP forward primer, $5^{\prime}$-cgagctggagccctgaaccgtcc- $3^{\prime}$ and MSP reverse primer, $5^{\prime}$-cggccgccgccaacgcgcag- $3^{\prime}$. For rt-MSP, the following oligonucleotides were used: forward primer, $5^{\prime}$-gg cgttcgtttgggattg- $3^{\prime}$; reverse primer, $5^{\prime}$-gccgacacgcgaactctaa- $3^{\prime}$; 
TaqMan ${ }^{\circledR}$ probe, FAM $5^{\prime}$-cgataaaaccgaacgacccgacga-3' TAMRA. PCR primers were obtained by Genescan (Freiburg, Germany). The probe was custom synthesised by Applied Biosystems (Foster City, CA, USA). Concentrations were $9 \mu \mathrm{m}$ for the forward, $3 \mu \mathrm{m}$ for the reverse primer and $2.5 \mu \mathrm{M}$ for the probe.

Two microlitres of the eluate containing the bisulphite-treated DNA has been used for each rt-MSP. Amplifications were carried out in 96-well plates in a 7000 Sequence detector (Applied Biosystems) in triplets using Universal Mastermix ${ }^{\circledR}$ (Applied Biosystems). The reaction volume was $25 \mu \mathrm{l}$. Thermal cycling was initiated by denaturation at $95^{\circ} \mathrm{C}$ for $10 \mathrm{~min}$. The PCR profile was $95^{\circ} \mathrm{C}$ for $15 \mathrm{~s}$ and $60^{\circ} \mathrm{C}$ for $1 \mathrm{~min}$ for a total of 50 cycles. Each plate contained patient samples and multiple water blanks as well as positive (MDA-MB-435 and MDA-MB-231 cell lines) and negative controls (MCF-7 cell line). The cell lines used have been well characterised regarding the methylation status of their ER promoter (Lapidus et al, 1998). Serial dilutions of the positive control DNA were used to generate a calibration curve for each analysis. To determine the relative levels of methylated ER promoter DNA in each sample, the values of ER promoter methylation were compared with the values of the internal reference, the housekeeping gene $A C T B$. Dilution series showed linearity of amplification down to $1: 10000$ for rt-MSP for methylated ER promoter as well as for $A C T B$.

\section{RESULTS}

To validate our approach and to confirm the findings by Issa et al (1994), we first examined primary invasive CRCs and lymph nodes with histologically proven metastasis from 14 patients with UICC stage III (any pT, pN1-2, M0) CRC. In 14 out of 14 (100\%) CRC and in 13 out of $14(93 \%)$ histologically positive lymph nodes, an aberrantly methylated ER promoter sequence was detected. None of the lymph nodes of the negative control group ( 0 out of 12), resected for non-neoplastic bowel disease (obstruction or ulcerative colitis), showed methylation of the ER promoter. Next, lymph nodes from 49 patients with UICC stage I or II CRC were analysed (Tables 1 and 2). The mean age of the patient population was 67 years (range 36-90), 25 patients were women and 24 men. Eleven patients had UICC stage I disease corresponding to TNM category pT2pN0 and 38 patients had UICC stage II with pT3pN0 $(n=37)$ and pT4pN0 $(n=1)$ tumours, respectively. In all, $9(18 \%)$ patients had cancer of the rectum, $12(24 \%)$ of the sigmoid colon, $7(14 \%)$ of the transverse and descending and $21(43 \%)$ of the ascending colon, respectively. At the last follow-up as of December 2006, the average follow-up was 64 months (range 47-79). Two patients with rectal cancer had received adjuvant radiochemotherapy.

Ten of 49 patients died during the follow-up period, three from disease recurrence, one from an accident and six from cardiovascular disease. In total, four patients developed recurrence (overall recurrence rate $8.2 \%$ ). One patient developed local and distant recurrence, one patient developed solely local recurrence and two patients developed solely distant metastases. Patients who died and did not develop tumour recurrence were treated as censored by statistical survival analysis.

Both patients with local recurrence were positive by rt-MSP (sensitivity $100 \%$, positive predictive value $13.3 \%$ ). They had well and moderately differentiated tumours of the rectum and sigmoid, respectively, and both had been staged as pT3 pN0 cM0 (UICC stage II). In both patients with local recurrence, six and seven lymph nodes had been examined. Local recurrence was diagnosed 11 and 33 months after initial diagnosis. Both patients died of their tumour recurrence.

Of the 49 patients tested, 15 (31\%) had ER methylation-positive lymph nodes. Thirteen of those $(86 \%)$ remained disease free and two $(14 \%)$ developed local recurrence. In the resected lymph nodes of 34 of the 49 patients (69\%), no ER promoter methylation could
Table I Summary of patient characteristics

\begin{tabular}{|c|c|c|}
\hline Patient characteristic & $n=49$ & \\
\hline Age mean (range) & 67 & range $36-90$ \\
\hline Male & 24 & $49 \%$ \\
\hline Female & 25 & $51 \%$ \\
\hline \multicolumn{3}{|l|}{ UICC stage } \\
\hline I & II & $22 \%$ \\
\hline$\|$ & 38 & $78 \%$ \\
\hline \multicolumn{3}{|l|}{ pT category } \\
\hline pT2 & II & $22 \%$ \\
\hline pT3 & 37 & $76 \%$ \\
\hline pT4 & 1 & $2 \%$ \\
\hline \multicolumn{3}{|l|}{ Grading } \\
\hline Well differentiated & 3 & $6 \%$ \\
\hline Moderately differentiated & 43 & $88 \%$ \\
\hline Poorly differentiated & 3 & $6 \%$ \\
\hline \multicolumn{3}{|l|}{ Tumour site } \\
\hline Ascending colon & 21 & $43 \%$ \\
\hline Transverse colon & 4 & $8 \%$ \\
\hline Descending colon & 3 & $6 \%$ \\
\hline Sigmoid colon & 12 & $24 \%$ \\
\hline Rectum & 9 & $18 \%$ \\
\hline \multicolumn{3}{|l|}{ MSI status } \\
\hline Positive & 7 & $26 \%$ \\
\hline Negative & 20 & $74 \%$ \\
\hline
\end{tabular}

MSI = microsatellite instability; UICC $=$ International Union Against Cancer

be detected and none of these patients experienced a local relapse. Of the 13 patients with positive ER promoter methylation in their resected lymph nodes and a disease-free follow-up, three had CRC UICC stage I and 10 UICC stage II. Regarding age, gender, tumour localisation, UICC stage, grading and the number of resected lymph nodes, there were no statistically significant differences between the patients with and without positive lymph nodes detected by ER promoter methylation.

None of the rt-MSP-negative patients ( 0 out of 34 ) developed local recurrence (specificity $72.3 \%$, negative predictive value $100 \%)$, but 2 out of $34(6 \%)$ rt-MSP-negative patients developed metastases in the liver and lung without evidence for lymph node or local recurrence. In these patients there was no methylation of the ER promoter in the lymph nodes removed at surgery. In 27 out of the 49 patients with CRC UICC stage I/II, MSI status, as previously assessed (Gerlach et al, 2006), was correlated with rt-MSP results and other clinical variables (Table 2); 7 out of 27 patients were MSI + . There was no statistical correlation between microsatellite status, rt-MSP results and local or distant recurrence or any other clinical variables.

\section{DISCUSSION}

According to clinical staging systems (UICC, Dukes and AstlerColler), the presence of lymph node metastases at the time of diagnosis predicts a poor prognosis for CRC patients. But even among patients with lymph nodes negative by histopathologic criteria ( $\mathrm{pN} 0), 10-20 \%$ will develop local tumour recurrence, which has been attributed to micrometastases outside the resected lymphatic drainage area. The most sensitive methods to detect micrometastases are immunohistochemistry (IHC) and nucleic acid-based methods. Only few studies could show micrometastases detected by IHC in lymph nodes of UICC stage I and II patients to correlate with disease recurrence and survival (Noura et al, 
Table 2 Case-specific clinicopathological parameters and experimental data on the number of investigated lymph nodes and corresponding rt-MSP results $(n=49)$

\begin{tabular}{|c|c|c|c|c|c|c|}
\hline Patient & pT category & Grading & MSI+ & Recurrence & Number of investigated lymph nodes & rt-MSP \\
\hline I & 3 & 2 & Yes & No & $1 \mid$ & - \\
\hline 2 & 3 & 2 & No & No & 18 & + \\
\hline 3 & 3 & 2 & No & No & 29 & + \\
\hline 4 & 3 & 2 & No & Local & 6 & + \\
\hline 5 & 3 & 2 & ND & No & 24 & - \\
\hline 6 & 2 & 2 & No & No & 5 & - \\
\hline 7 & 3 & 2 & ND & No & 7 & - \\
\hline 8 & 3 & 2 & No & Distant & 14 & - \\
\hline 9 & 3 & 2 & ND & No & 5 & - \\
\hline 10 & 2 & I & ND & No & 9 & - \\
\hline | | & 3 & 2 & No & No & 5 & + \\
\hline 12 & 2 & 2 & Yes & No & 9 & - \\
\hline 13 & 3 & 2 & No & No & 4 & - \\
\hline 14 & 2 & 2 & No & No & 11 & - \\
\hline 15 & 3 & 3 & No & No & 16 & - \\
\hline 16 & 3 & 2 & ND & No & 4 & - \\
\hline 17 & 4 & 2 & Yes & No & 17 & + \\
\hline 18 & 3 & 2 & ND & No & I & - \\
\hline 19 & 3 & 2 & ND & No & 3 & - \\
\hline 20 & 3 & 2 & No & No & 10 & - \\
\hline 21 & 3 & 2 & ND & No & 7 & - \\
\hline 22 & 3 & 2 & No & No & 9 & - \\
\hline 23 & 2 & 2 & Yes & Distant & 4 & - \\
\hline 24 & 3 & 2 & ND & No & 2 & - \\
\hline 25 & 2 & 2 & ND & No & 2 & - \\
\hline 26 & 3 & 2 & No & No & 5 & + \\
\hline 27 & 3 & 2 & ND & No & 4 & - \\
\hline 28 & 2 & 2 & Yes & No & 19 & + \\
\hline 29 & 3 & 2 & ND & No & 7 & - \\
\hline 30 & 3 & 2 & ND & No & 4 & + \\
\hline 31 & 3 & 1 & Yes & Local and distant & 7 & + \\
\hline 32 & 3 & 2 & ND & No & 5 & - \\
\hline 33 & 3 & 2 & No & No & 5 & + \\
\hline 34 & 3 & 3 & No & No & 7 & + \\
\hline 35 & 2 & 2 & No & No & 10 & + \\
\hline 36 & 3 & 2 & Yes & No & 17 & - \\
\hline 37 & 3 & 2 & No & No & 14 & - \\
\hline 38 & 3 & I & No & No & 6 & + \\
\hline 39 & 3 & 2 & ND & No & 21 & - \\
\hline 40 & 3 & 2 & ND & No & 12 & - \\
\hline 41 & 3 & 2 & ND & No & 18 & - \\
\hline 42 & 3 & 2 & No & No & 6 & - \\
\hline 43 & 2 & 3 & ND & No & 13 & - \\
\hline 44 & 2 & 2 & No & No & 9 & + \\
\hline 45 & 3 & 2 & ND & No & 5 & - \\
\hline 46 & 2 & 2 & ND & No & 16 & - \\
\hline 47 & 2 & 2 & ND & No & 22 & - \\
\hline 48 & 3 & 2 & ND & No & 14 & - \\
\hline 49 & 3 & 2 & No & No & 9 & + \\
\hline
\end{tabular}

$\mathrm{MSI}+=$ microsatellite instability; $\mathrm{ND}=$ not determined; rt-MSP = real-time methylation-specific PCR.

2002a, b; Lee et al, 2006; Messerini et al, 2006). These conflicting data may be due to the specificity and sensitivity of proteins used for detection as well as the variable thickness and number of tissue sections analysed (Nordgard et al, 2003). Therefore, we did not compare the results of rt-MSP with IHC studies.

In addition, there have been several reports on the detection of CK mRNA by RT-PCR. Some studies showed a correlation between CK 20 expression detected by RT-PCR and disease recurrence as well as overall survival, whereas other studies did not (Ichikawa et al, 1998; Liefers et al, 1998; Sanchez-Cespedes et al, 1999; Bernini et al, 2000; Miyake et al, 2001; Noura et al, 2002a, b; Merrie et al, 2003; Ho et al, 2004; Lassmann et al, 2004; Pellise et al, 2004; Lee et al, 2006). As CK expression is also found in granulocytes and normal blood cells, the highly sensitive RT - PCR may produce false-positive results as described by Bostick et al
(1998), Jung et al (1999) and Bustin et al (2000). This hypothesis is supported by a report by Rosenberg et al (2002), who found CK-positive cells on histological examination exclusively on the outside of lymph nodes in almost $30 \%$ of RT-PCR-positive specimens. Other markers, including CEA, MUC2, GCC, matrilysin, $\beta$-HCG and others, have been explored to detect lymph node micrometastases by RT - PCR and yielded inconsistent results (Ichikawa et al, 1998; Cagir et al, 1999; Bernini et al, 2000). Expression levels of these different markers can vary considerably among tumour specimens of the same entity. Therefore, these markers have to be compared with the primary tumour (Hanski et al, 1997; Waldman et al, 1998). In contrast, the ER promoter methylation is present in almost $100 \%$ of CRC. Also, in our population, all primary CRCs were positive for ER promoter methylation. Next, we were able to show ER promoter methylation 
as a good marker of lymph node metastases. To use this marker for the detection of micrometastases we analysed lymph nodes from a study population with UICC stage I and II CRCs. Instead of expression levels here we detected gene promoter methylation by PCR-based methods. The high stability of DNA compared with RNA is one of the main advantages of DNA-based detection methods, which therefore can be applied to the analysis of paraffin-embedded tissues. We demonstrated rt-MSP of DNA from paraffin-embedded lymph node tissue as a robust and practicable method to detect micrometastases.

The high stability of DNA compared with RNA is one of the main advantages of DNA-based detection methods, which therefore can be applied to the analysis of paraffin-embedded tissues. We demonstrated rt-MSP of DNA from paraffin-embedded lymph node tissue as a robust and practicable method to detect micrometastases.

The high negative predictive value was achieved, because none of the 33 patients negative for ER promoter methylation in their lymph nodes developed local recurrence. On the other hand, not all MSP-positive patients developed local recurrence during followup. This limitation might in part be explained by a too short follow-up period, the heterogeneity of the study population in terms of the number of investigated lymph nodes or other molecular factors, respectively. The small number of recurrences is another limitation that does not allow a statistical multivariable analysis and results in a low positive predictive value.

Molecular factors have recently been shown to predict disease outcome as distinct genetic subtypes of CRC are defined (Shen et al, 2007). Especially, MSI status has been correlated with recurrence and prognosis of CRC (Gryfe et al, 2000; Kim et al, 2007). Therefore, we compared the MSI status of primary tumours in a subset of patients with the presence of ER promoter methylation in lymph nodes and disease recurrence. Of 27 patients, seven were MSI +, but showed no clear-cut trend for rt-MST results and disease recurrence. On account of the small number of recurrences and the limited statistical significance we did not compare molecular variables other than MSI.

Another reason for the high rate of detected micrometastases by rt-MSP compared with recurrences might be the high sensitivity of rt-MSP, which may detect single tumour cells in a lymph node that might not have the potential to develop to a clinically relevant tumour. This obviously raises the question of the clinical significance of micrometastases for the individual patient. However, the most likely explanation for the lower positive predictive value seems to lie in a potentially complete resection of all micrometastases bearing lymph nodes at surgery.

Lymph node and distant metastases represent two different routes of CRC progression. Whereas the first is probably due to a spread of tumour cells through the local lymph system, the latter arises from circulating tumour cells. Histopathological lymph node involvement is a predictor of disease recurrence. Generally, the route of tumour spread is dependant on the overall tumour load. This interpretation is supported by the close correlation between the quantitative level of CEA transcripts in serum and tumour stage (Ho et al, 2004; Ohlsson et al, 2006). For local recurrence, ER promoter methylation in lymph nodes could narrow down the patients at risk but not for distant metastases. Overall, the correlation of micrometastatic lymph node involvement together with tumour DNA in plasma from CRC patients may better assess the overall risk of disease recurrence.

In summary, rt-MSP for ER promoter methylation may represent a sensitive and robust method to identify patients with UICC stage I and II CRC at risk for local recurrence. Positive patients have a risk for local recurrence similar to UICC stage III.

\section{REFERENCES}

Bernini A, Spencer M, Frizelle S, Madoff RD, Willmott LD, McCormick SR, Niehans GA, Ho SB, Kratzke RA (2000) Evidence for colorectal cancer micrometastases using reverse transcriptase-polymerase chain reaction analysis of MUC2 in lymph nodes. Cancer Detect Prev 24: 72-79

Bostick PJ, Chatterjee S, Chi DD, Huynh KT, Giuliano AE, Cote R, Hoon DS (1998) Limitations of specific reverse-transcriptase polymerase chain reaction markers in the detection of metastases in the lymph nodes and blood of breast cancer patients. J Clin Oncol 16: 2632-2640

Bustin SA, Gyselman VG, Siddiqi S, Dorudi S (2000) Cytokeratin 20 is not a tissue-specific marker for the detection of malignant epithelial cells in the blood of colorectal cancer patients. Int J Surg Investig 2: $49-57$

Cagir B, Gelmann A, Park J, Fava T, Tankelevitch A, Bittner EW, Weaver EJ, Palazzo JP, Weinberg D, Fry RD, Waldman SA (1999) Guanylyl cyclase C messenger RNA is a biomarker for recurrent stage II colorectal cancer. Ann Intern Med 131: 805-812

de Maat MF, van de Velde CJ, van der Werff MP, Putter H, Umetani N, Klein-Kranenbarg EM, Turner RR, van Krieken JH, Bilchik A, Tollenaar RA, Hoon DS (2008) Quantitative analysis of methylation of genomic loci in early-stage rectal cancer predicts distant recurrence. J Clin Oncol 26: $2327-2335$

Eads CA, Lord RV, Kurumboor SK, Wickramasinghe K, Skinner ML, Long TI, Peters JH, DeMeester TR, Danenberg KD, Danenberg PV, Laird PW, Skinner KA (2000) Fields of aberrant CpG island hypermethylation in Barrett's esophagus and associated adenocarcinoma. Cancer Res 60: $5021-5026$

Esteller M, Corn PG, Baylin SB, Herman JG (2001) A gene hypermethylation profile of human cancer. Cancer Res 61: 3225-3229

Futamura M, Takagi Y, Koumura H, Kida H, Tanemura H, Shimokawa K, Saji S (1998) Spread of colorectal cancer micrometastases in regional lymph nodes by reverse transcriptase-polymerase chain reactions for carcinoembryonic antigen and cytokeratin 20. J Surg Oncol 68: $34-40$

Gerlach U, Kayser G, Walch A, Hopt U, Schulte-Mönting J, Werner M, Lassmann S (2006) Centrosome-, chromosomal-passenger- and cell-cycle-associated mRNAs are differentially regulated in the development of sporadic colorectal cancer. J Pathol 208: $462-472$

Gryfe R, Kim H, Hsieh ET, Aronson MD, Holowaty EJ, Bull SB, Redston M, Gallinger S (2000) Tumor microsatellite instability and clinical outcome in young patients with colorectal cancer. N Engl J Med 342: 69-77

Hanski C, Riede E, Gratchev A, Foss HD, Bohm C, Klussmann E, Hummel M, Mann B, Buhr HJ, Stein H, Kim YS, Gum J, Riecken EO (1997) MUC2 gene suppression in human colorectal carcinomas and their metastases: in vitro evidence of the modulatory role of DNA methylation. Lab Invest 77: $685-695$

Herman JG, Jen J, Merlo A, Baylin SB (1996) Hypermethylation-associated inactivation indicates a tumor suppressor role for p15INK4B. Cancer Res 56: $722-727$

Ho SB, Hyslop A, Albrecht R, Jacobson A, Spencer M, Rothenberger DA, Niehans GA, D'Cunha J, Kratzke RA (2004) Quantification of colorectal cancer micrometastases in lymph nodes by nested and real-time reverse transcriptase-PCR analysis for carcinoembryonic antigen. Clin Cancer Res 10: $5777-5784$

Ichikawa Y, Ishikawa T, Momiyama N, Yamaguchi S, Masui H, Hasegawa S, Chishima T, Takimoto A, Kitamura H, Akitaya T, Hosokawa $\mathrm{T}$, Mitsuhashi M, Shimada H (1998) Detection of regional lymph node metastases in colon cancer by using RT-PCR for matrix metalloproteinase 7, matrilysin. Clin Exp Metastasis 16: 3-8

Issa JP, Ottaviano YL, Celano P, Hamilton SR, Davidson NE, Baylin SB (1994) Methylation of the oestrogen receptor CpG island links ageing and neoplasia in human colon. Nat Genet 7: 536-540

Issa JP, Zehnbauer BA, Civin CI, Collector MI, Sharkis SJ, Davidson NE, Kaufmann SH, Baylin SB (1996) The estrogen receptor CpG island is methylated in most hematopoietic neoplasms. Cancer Res 56: 973-977

Jass JR (2007) Classification of colorectal cancer based on correlation of clinical, morphological and molecular features. Histopathology 50: 113-130 
Jung R, Petersen K, Kruger W, Wolf M, Wagener C, Zander A, Neumaier M (1999) Detection of micrometastasis by cytokeratin 20 RT-PCR is limited due to stable background transcription in granulocytes. $\mathrm{Br} \mathrm{J}$ Cancer 81: $870-873$

Kim GP, Colangelo LH, Wieand HS, Paik S, Kirsch IR, Wolmark N, Allegra CJ (2007) Prognostic and predictive roles of high-degree microsatellite instability in colon cancer: a National Cancer Institute-National Surgical Adjuvant Breast and Bowel Project Collaborative Study. J Clin Oncol 25: 767-772

Landis SH, Murray T, Bolden S, Wingo PA (1998) Cancer statistics, 1998. CA Cancer J Clin 48: 6-29

Lapidus RG, Nass SJ, Butash KA, Parl FF, Weitzman SA, Graff JG, Herman JG, Davidson NE (1998) Mapping of ER gene CpG island methylationspecific polymerase chain reaction. Cancer Res 58: 2515-2519

Lassmann S, Bauer M, Rosenberg R, Nekarda H, Soong R, Ruger R, Hofler $\mathrm{H}$, Werner M (2004) Identification of occult tumor cells in node negative lymph nodes of colorectal cancer patients by cytokeratin 20 gene and protein expression. Int J Colorectal Dis 19: $87-94$

Lee MR, Hong CW, Yoon SN, Lim SB, Park KJ, Lee MJ, Kim WH, Park JG (2006) Isolated tumor cells in lymph nodes are not a prognostic marker for patients with stage I and stage II colorectal cancer. J Surg Oncol 93: 13-18; discussion 18-9

Lenz HJ, Danenberg KD, Leichman CG, Florentine B, Johnston PG, Groshen S, Zhou L, Xiong YP, Danenberg PV, Leichman LP (1998) p53 and thymidylate synthase expression in untreated stage II colon cancer: associations with recurrence, survival, and site. Clin Cancer Res 4: $1227-1234$

Liefers GJ, Cleton-Jansen AM, van de Velde CJ, Hermans J, van Krieken JH, Cornelisse CJ, Tollenaar RA (1998) Micrometastases and survival in stage II colorectal cancer. $N$ Engl J Med 339: 223-228

Merrie AE, van Rij AM, Dennett ER, Phillips LV, Yun K, McCall JL (2003) Prognostic significance of occult metastases in colon cancer. Dis Colon Rectum 46: $221-231$

Messerini L, Cianchi F, Cortesini C, Comin CE (2006) Incidence and prognostic significance of occult tumor cells in lymph nodes from patients with stage IIA colorectal carcinoma. Hum Pathol 37: 1259-1267

Miyake Y, Yamamoto H, Fujiwara Y, Ohue M, Sugita Y, Tomita N, Sekimoto M, Matsuura N, Shiozaki H, Monden M (2001) Extensive micrometastases to lymph nodes as a marker for rapid recurrence of colorectal cancer: a study of lymphatic mapping. Clin Cancer Res 7: $1350-1357$
Nordgard O, Aloysius TA, Todnem K, Heikkila R, Ogreid D (2003) Detection of lymph node micrometastases in colorectal cancer. Scand J Gastroenterol 38: $125-132$

Noura S, Yamamoto H, Miyake Y, Kim B, Takayama O, Seshimo I, Ikenaga M, Ikeda M, Sekimoto M, Matsuura N (2002a) Immunohistochemical assessment of localization and frequency of micrometastases in lymph nodes of colorectal cancer. Clin Cancer Res 8: 759-767

Noura S, Yamamoto H, Ohnishi T, Masuda N, Matsumoto T, Takayama O, Fukunaga H, Miyake Y, Ikenaga M, Ikeda M, Sekimoto M, Matsuura N (2002b) Comparative detection of lymph node micrometastases of stage II colorectal cancer by reverse transcriptase polymerase chain reaction and immunohistochemistry. J Clin Oncol 20: 4232-4241

Ohlsson L, Hammarstrom ML, Israelsson A, Naslund L, Oberg A, Lindmark G (2006) Biomarker selection for detection of occult tumour cells in lymph nodes of colorectal cancer patients using real-time quantitative RT-PCR. Br J Cancer 95: 218-225

Pellise M, Castells A, Gines A, Agrelo R, Sole M, Castellvi-Bel S, Fernandez-Esparrach G, Llach J, Esteller M, Bordas JM (2004) Detection of lymph node micrometastases by gene promoter hypermethylation in samples obtained by endosonography- guided fine-needle aspiration biopsy. Clin Cancer Res 10: $4444-4449$

Rosenberg R, Hoos A, Mueller J, Baier P, Stricker D, Werner M, Nekarda H, Siewert JR (2002) Prognostic significance of cytokeratin-20 reverse transcriptase polymerase chain reaction in lymph nodes of nodenegative colorectal cancer patients. J Clin Oncol 20: 1049-1055

Sanchez-Cespedes M, Esteller M, Hibi K, Cope FO, Westra WH, Piantadosi S, Herman JG, Jen J (1999) Molecular detection of neoplastic cells in lymph nodes of metastatic colorectal cancer patients predicts recurrence. Clin Cancer Res 5: $2450-2454$

Shen L, Toyota M, Kondo Y, Lin E, Zhang L, Guo Y, Hernandez NS, Chen X, Ahmed S, Konishi K, Hamilton SR (2007) Integrated genetic and epigenetic analysis identifies three different subclasses of colon cancer. Proc Natl Acad Sci USA 104: 18654-18659

Waldman SA, Barber M, Pearlman J, Park J, George R (1998) Heterogeneity of guanylyl cyclase $\mathrm{C}$ expressed by human colorectal cancer cell lines in vitro. Cancer Epidemiol Biomarkers Prev 7: 505-514

Yagci G, Unlu A, Kurt B, Can MF, Kaymakcioglu N, Cetiner S, Tufan T (2007) Detection of micrometastases and skip metastases with ex vivo sentinel node mapping in carcinoma of the colon and rectum. Int $J$ Colorectal Dis 22: $167-173$ 